\title{
Possible etiology of improvements in both quality of life and overlapping gastroesophageal reflux disease by proton pump inhibitor treatment in a prospective randomized controlled trial
}

Hubert Mönnikes ${ }^{1 *}$, Thomas Schwan², Christo van Rensburg ${ }^{3}$, Andrzej Straszak ${ }^{4}$, Carmen Theek ${ }^{5}$, Reinhold Lühmann², Peter Sander ${ }^{2}$ and Anne Tholen ${ }^{6}$

\begin{abstract}
Background: Symptoms suggestive of functional dyspepsia (FD) and irritable bowel syndrome (IBS) frequently overlap with those of gastroesophageal reflux disease. Despite the high prevalence of symptomatic overlap, the underlying etiology remains poorly defined. We assessed the correlation of symptomatic relief and health-related quality of life (HRQoL) with healing of reflux esophagitis to further derive insights into the underlying etiology.

Methods: 626 patients with reflux esophagitis were enrolled into one of two treatment groups (classical healing concept or the complete remission concept) to investigate differences in treatment intensity. Patients were treated with pantoprazole until esophageal mucosal healing. Remission was followed for up to 6 months without treatment. Gastro-intestinal symptoms and HRQoL were analyzed using disease-specific, psychometrically validated patient-reported outcome instruments (ReQuest ${ }^{T M}$, GERDyzer ${ }^{T M}$ ).

Results: Symptomatic burden reflected by ReQuest ${ }^{\mathrm{TM}}$ substantially decreased from baseline to end of treatment by $83 \%$ and $88 \%$ in either treatment group, respectively. ReQuest ${ }^{\mathrm{TM}}$ scores significantly decreased in patients with or without heartburn and in those with symptoms suggestive of FD and IBS, indicating response of all symptom categories to treatment $(p<0.005)$. Therapy-associated relief of symptoms was paralleled by substantial gains in HRQOL, which continued to stabilize post-treatment.

Conclusions: Pantoprazole is effective in relieving upper and lower gastro-intestinal symptoms overlapping with erosive esophagitis, and provides sustained improvement in HRQoL post-treatment. Our results propose a link between both healing of erosive esophagitis and the slower remission of upper and lower gastro-intestinal symptoms. Since the improvement observed is likely to be multifactorial, the possibility for an immune-mediated etiology and identification of putative susceptibility factors by genome-wide association study may provide focus for future research.
\end{abstract}

Trial registration: ClinicalTrials.gov identifier: NCT00325676.

Keywords: Gastroesophageal reflux disease (GERD), Functional dyspepsia (FD), Irritable bowel syndrome (IBS), Inflammatory bowel diseases (IBD), Proton pump inhibitor (PPI)

\footnotetext{
* Correspondence: moennikes@web.de

'Department of Medicine and Institute of Neurogastroenterology, Academic

Teaching Hospital Martin Luther, Charité - Universitätsmedizin Berlin,

Caspar-Theyß-Str. 27-31, 14193, Berlin, Germany

Full list of author information is available at the end of the article
} 


\section{Background}

Gastroesophageal reflux disease (GERD) is highly prevalent in the general population. In most cases, GERD is considered a chronic disorder requiring long-term acid suppression to maintain symptomatic remission and/or healing of erosive esophagitis [1,2]. GERD significantly impacts on health-related quality of life (HRQoL) [3,4]. Veldhyzen van Zanten et al. (2012) reported a close association between increased patient satisfaction, relief of GERD symptoms, and improved HRQoL, with relevant associations similar to those in other chronic diseases [5]. Additional investigations have been conducted for functional bowel disorders such as irritable bowel syndrome (IBS), concluding that therapeutic response is associated with improvements in HRQoL [6]. These reports focus on qualitative or statistical correlations, but do not propose any mechanistic psychological concept for the observed concordance.

Symptomatic overlap of GERD with gastro-intestinal (GI) co-morbidity suggestive of functional dyspepsia (FD) or irritable bowel syndrome (IBS) [7-10] is thought, amongst other explanations, to contribute to partial or complete non-response to a standard dose of proton pump inhibitor (PPI) in a significant subset of patients $[3,5,11]$. However, overlap does not appear to be static over time as symptom categories tend to fluctuate during long-term follow-up $[8,12]$. Causative pathomechanisms currently considered include inflammatory etiologies [13,14], altered intestinal motility [15], and visceral hypersensitivity [16], each suggesting the need for individualized therapeutic approaches in specific patient groups.

Cumulative clinical and scientific discoveries, along with regulatory requirements of demonstrating statistical significance for efficacy claims, have resulted in increasingly narrowly defined indications and stratified patient populations in clinical trials. Since such an approach might not reflect the actual patient population seeking medical help, it might be useful to study the pharmacological management of a real-life scenario [17], which would allow for the investigation of an overlap between GERD and symptoms suggestive of FD and IBS. Although such a study might carry the elevated risk of observing only a partial response to PPI treatment in these less stringently selected patients [5], such a design could reveal additional insights into the inter-relationship between perceived symptoms and HRQoL, and the pathophysiological relatedness of, or separation between, GERD, FD, IBS and possibly earlystage inflammatory bowel diseases (IBD).

In the current study, we therefore investigated a patient population that closely resembles the general population affected by endosopically-confirmed GERD, which overlaps with upper and lower GI symptomatology. In addition, we evaluated two treatment groups, which modelled differences in treatment intensity and compliance. We further hypothesized that treatment intensity would influence patterns of relapsing erosive esophagitis, and that the analysis of the temporal development of overlap during treatment and remission could shed additional insights into an underlying etiology.

\section{Methods}

\section{Study design and patients}

The design and primary results of this prospective clinical trial (ClinicalTrials.gov identifier: NCT00325676) have been previously described elsewhere [18]. This report includes prospectively defined subgroup analyses of therapy-associated changes of GI symptomatology and HRQoL. In brief, this randomized, multicenter, multinational, parallel group study (June 2006 to May 2007) was conducted in patients with GERD diagnosed endoscopically according to the Los Angeles classification (LA grade A-D) (full inclusion and exclusion criteria have been previously presented [18]). To assess the treatment effects based on duration and intensity of PPI administration, patients were randomized to two different treatment concepts: classical healing $(\mathrm{CH})$ and complete remission (CR) (Figure 1). The $\mathrm{CH}$ group was treated up to 8 weeks until esophageal healing only (according to the LA classification), whereas the CR group was treated up to 16 weeks until 'complete remission' occurred. This was defined as esophageal healing and a ReQuest ${ }^{\text {tw }}$ (Reflux Questionnaire, Nycomed GmbH, Nycomed: a Takeda Company, Konstanz, Germany) -GI score below the predefined symptom threshold [19]. The trial was further divided into two periods: a treatment phase and a subsequent observational phase. During the treatment phase, patients were administered pantoprazole $40 \mathrm{mg}$ od until resolution of GERD as pre-specified for each group. Healed patients entered an observational phase, which consisted of clinical follow-up for up to 6 months without PPI treatment and monitoring for endoscopically-confirmed relapse of reflux esophagitis according to the LA classification. To further assess concurrent symptoms affecting the upper and lower GI tract, a questionnaire was implemented asking for heartburn and modified symptomatic Rome II/III criteria, the latter suggesting diagnoses of FD and IBS [18].

The trial was performed in accordance with the Declaration of Helsinki and the International Conference on Harmonisation-Good Clinical Practice (ICH-GCP), and was approved by the independent ethics committees (Commission of Bioethics of Silesian Medical Chamber in Katowice [Poland]; Pharma Ethics, and University of the Free State Ethics Committee [South Africa]; Ärztekammer der Ethikkommission Schleswig-Holstein [Germany]) for 

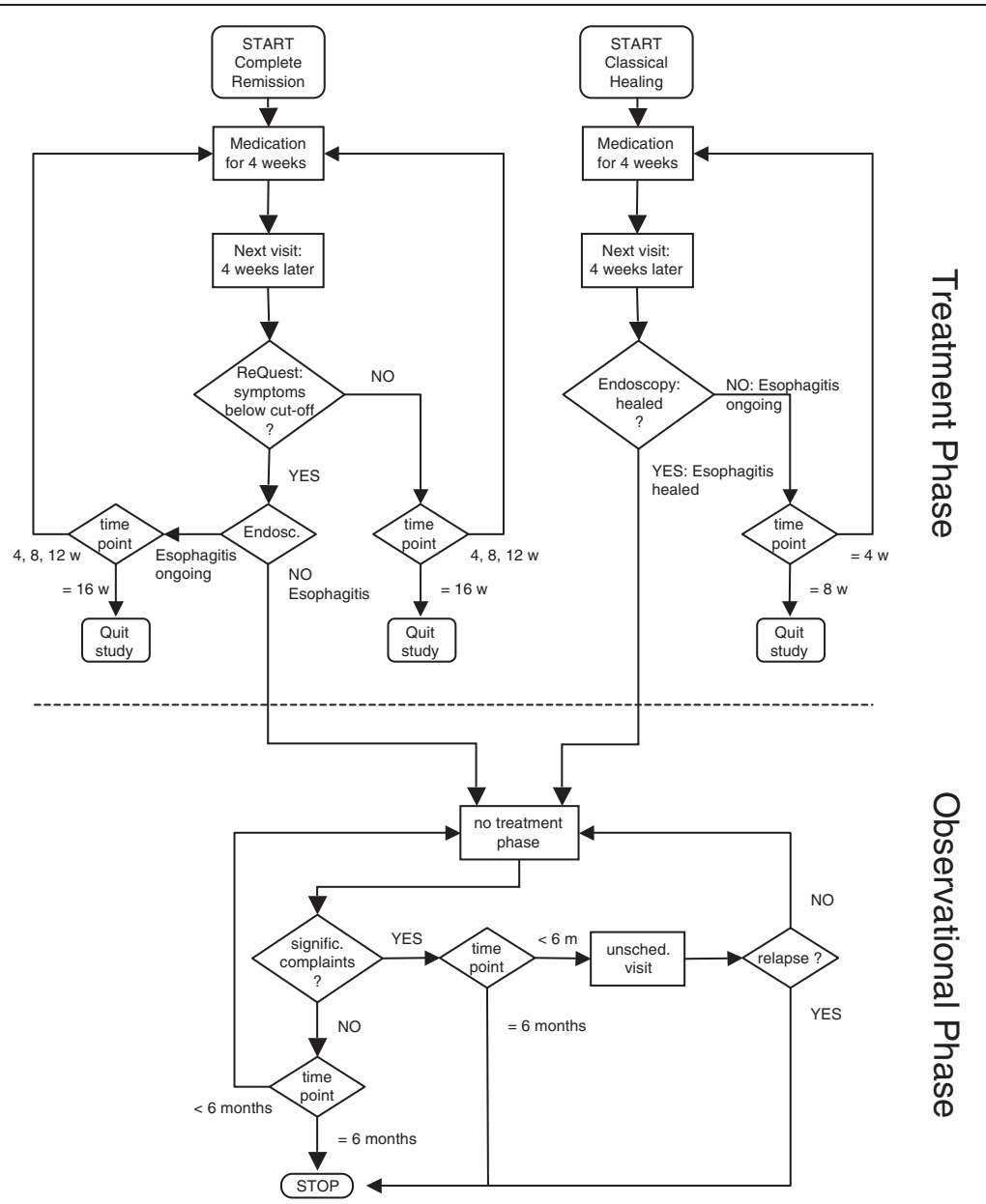

Figure 1 Treatment algorithm. START, V0; STOP, last visit of Observational Phase; m, months; w, weeks.

each participating center. Prior to participation, all patients provided written informed consent.

\section{Assessments of $\mathrm{Gl}$ symptoms (ReQuest ${ }^{\mathrm{TM}}$ )}

The course of GI symptom profiles was measured over time using ReQuest ${ }^{\mathrm{TM}}$. ReQuest ${ }^{\mathrm{TM}}$ is a disease-specific, self-administered and psychometrically validated patientreported outcome instrument designed to assess the course of GERD symptoms [19]. It is divided into two subscales, ReQuest ${ }^{\mathrm{TM}}$-GI (including dimensions 'acid complaints', 'upper abdominal/stomach complaints,' 'lower abdominal/digestive complaints' and 'nausea') and ReQuest ${ }^{\mathrm{TM}}$-WSO (assessing dimensions 'general well-being', 'sleep disturbances' and 'other complaints'). Dimensions were assessed for frequency and intensity, except for 'general well-being' where only intensity was recorded.

\section{Assessments of HRQoL (GERDyzer ${ }^{\mathrm{TM}}$ )}

Treatment-induced changes in HRQoL were assessed using GERDyzer ${ }^{\mathrm{TM}}$ (GERD Analyzer Scale, Nycomed GmbH,
Nycomed: a Takeda Company, Konstanz, Germany). GERDyzer $^{\mathrm{TM}}$ is a disease-specific, self-administered and psychometrically validated patient-reported outcome instrument that was developed to investigate the impact of GERD on HRQoL [4]. GERDyzer ${ }^{\text {TM }}$ comprises 10 dimensions of quality of life: 'general well-being', 'pain/discomfort', 'physical health', 'energy', 'daily activities', 'leisure activities', 'social life', 'diet/eating/drinking habits,' 'mood and sleep', and satisfaction aspects.

\section{Statistical analysis}

In general, descriptive summary statistics were determined showing parameters for location and dispersion for continuous parameters, and frequencies and percentages for categories. The course over time for mean values of parameters is displayed graphically by line plots comparing the respective groups of patients.

ReQuest $^{\mathrm{TM}}$ total scores were analyzed using descriptive statistics. Between-group comparisons for patients with or without heartburn, with or without FD, and with or 
without IBS were performed using the Wilcoxon ranksum test.

HRQoL measured by GERDyzer ${ }^{\mathrm{rt}}$ was evaluated using explorative methods. The main analysis investigated GERDyzer $^{\mathrm{Tm}}$ mean sum scores. Sum scores pertaining to the observational phase were compared between both treatment groups using the Wilcoxon rank-sum test.

\section{Results}

\section{Patient characteristics}

Of the 634 patients who initially received study medication, 316 (49.8\%) were treated according to the $\mathrm{CH}$ concept and 318 (50.2\%) according to the CR concept. Out of the safety set of 634 patients, 539 individuals (85.0\%) were diagnosed with erosive esophagitis LA grade A-B and 95 individuals (15.0\%) with erosive esophagitis LA grade $\mathrm{C}-\mathrm{D}$. The intention-to-treat (ITT) population comprised 626 patients, with 313 patients being allocated to each of the two treatment concepts $(\mathrm{CH}$ or CR). Of these, 87 patients were enrolled in Poland $(\mathrm{CH}$ 45, CR 42), 301 in South Africa (CH 160, CR 141), and 238 in Germany ( $\mathrm{CH} \mathrm{108,} \mathrm{CR} \mathrm{130).} \mathrm{Most} \mathrm{patients} \mathrm{were}$ of white ethnicity ( $\mathrm{CH} 78.6 \%$, CR $80.8 \%)$. FD-like complaints were diagnosed at baseline in $65.2 \%$ and $64.2 \%$, and IBS-like co-morbidity existed in $14.1 \%$ and $13.1 \%$ of the $\mathrm{CH}$ and $\mathrm{CR}$ groups, respectively (Table 1 ). The number of patients in subgroups of FD and subgroups of IBS tended to be rather small (data on file). Approximately one-quarter of patients in each treatment group were current smokers. Neither ReQuest ${ }^{\mathrm{Tw}}$ total scores nor

Table 1 Demographic data and clinical disposition at baseline (ITT, $\mathrm{N}=626$ )

\begin{tabular}{|c|c|c|c|}
\hline \multicolumn{2}{|l|}{ Variable } & $\begin{array}{l}\text { CH group } \\
(N=313)\end{array}$ & \multirow{2}{*}{$\begin{array}{l}\text { CR group } \\
(\mathbf{N}=\mathbf{3 1 3}) \\
170(54.3)\end{array}$} \\
\hline Gender, $n(\%)$ & Male & $167(53.4)$ & \\
\hline & Female & $146(46.6)$ & $143(45.7)$ \\
\hline Age [years], mean (SD) & & $50.8(14.6)$ & $48.8(14.0)$ \\
\hline Weight [kg], mean (SD) & & $81.8(16.4)$ & $83.4(17.4)$ \\
\hline BMI $\left[\mathrm{kg} / \mathrm{m}^{2}\right]$, mean (SD) & & $28.0(5.1)$ & $28.6(5.7)$ \\
\hline \multirow[t]{4}{*}{ Race, $n(\%)$} & Asian & $14(4.5)$ & $7(2.2)$ \\
\hline & Black & $13(4.2)$ & $17(5.4)$ \\
\hline & White & $246(78.6)$ & $253(80.8)$ \\
\hline & Other & $40(12.8)$ & $36(11.5)$ \\
\hline \multirow[t]{2}{*}{ Gl comorbidities, n (\%) } & Dyspepsia-like & $204(65.2)$ & $201(64.2)$ \\
\hline & IBS-like & $44(14.1)$ & $41(13.1)$ \\
\hline Current smoker, $n$ (\%) & & $79(25.2)$ & $83(26.5)$ \\
\hline ReQuest $^{\mathrm{TM}}$ total score & & 10.23 & 11.37 \\
\hline GERDyzer $^{\text {TM }}$ sum score & & 46.12 & 49.45 \\
\hline
\end{tabular}

CH classical healing, CR complete remission, IBS irritable bowel syndrome, ITT intention-to-treat, $N$ number of patients, $B M I$ body mass index, $S D$ standard deviation.
GERDyzer $^{\mathrm{rat}}$ sum scores were notably different at baseline in the treatment arms.

\section{Therapy-associated change in Gl symptoms}

The change of the GI symptom burden over time as evaluated by ReQuest ${ }^{\mathrm{tm}}$ is shown in Figure 2. For both treatment groups, the ReQuest ${ }^{\text {tix }}$ total scores were significantly lower at the end of pantoprazole treatment $(\mathrm{CH}$ 2.14, CR 1.76) than at baseline ( $\mathrm{CH} 10.23, \mathrm{CR} 11.37)$. This resembles a clinically significant decrease of the total score by $79 \%$ in the $\mathrm{CH}$ group and by $85 \%$ in the $\mathrm{CR}$ group. This finding was paralleled by a similar time course for the two subscales ReQuest ${ }^{\mathrm{tm}}$-GI and ReQuest $^{\text {tix }}$-WSO. The ReQuest ${ }^{\text {tim }}$-GI score substantially decreased from baseline ( $\mathrm{CH}$ 6.74, $\mathrm{CR}$ 7.29) to the end of treatment $(\mathrm{CH} 1.12$, $\mathrm{CR}$ 0.84), reflective of a decrease of the GI score by $83 \%$ in the $\mathrm{CH}$ group and by $88 \%$ in the CR group (Figure 2).

To evaluate the influence of concurrent symptoms affecting the upper and lower GI tract, a joint analysis of both treatment groups was performed. At baseline, higher ReQuest ${ }^{\mathrm{Tw}}$ total scores were identified in patients with concurrent symptoms suggestive of FD (12.45) or IBS (14.47) than in patients with (11.37) or without (5.53) heartburn. At the end of pantoprazole treatment, ReQuest ${ }^{\mathrm{mm}}$ scores notably decreased in patients with (4.65) or without heartburn (1.41), and in those with symptoms suggestive of FD (4.36) or IBS (4.04), indicating response of all symptom categories to PPI treatment. Interestingly, the trend for higher total scores at baseline from concomitant heartburn (11.37) to IBS (14.47) was inverted post-treatment (heartburn 4.65, IBS 4.04). Comparison of ReQuest ${ }^{\mathrm{mi}}$ total scores among groups of patients with or without heartburn, FD, or IBS was statistically significant (all, $\mathrm{p}<0.005$ ).

In order to further evaluate the appropriateness of both healing concepts, courses over time of the ReQuest $^{\mathrm{tm}}$ total score and its subscales were plotted for both the $\mathrm{CH}$ and $\mathrm{CR}$ groups in conjunction with total scores of a subgroup deduced from $\mathrm{CH}$ patients who were endoscopically healed but not in complete remission. As can be seen from Figure 2, ReQuest ${ }^{\text {ti }}$ scores were almost 2-fold higher for patients endoscopically healed but not in complete remission than for patients in either the $\mathrm{CH}$ or $\mathrm{CR}$ groups, suggesting the clinical relevance of treatment aimed at full symptomatic remission in addition to esophageal mucosal healing.

\section{Therapy-associated change in $\mathrm{HRQoL}$}

Data from the HRQoL questionnaire GERDyzer ${ }^{\mathrm{rm}}$ were available from 606 patients at baseline, with data from $3.3 \%$ of patients missing (ITT). Overall, the significant decrease in GERDyzer ${ }^{\text {Tu }}$ mean sum scores during pantoprazole treatment indicated that HRQoL improved 


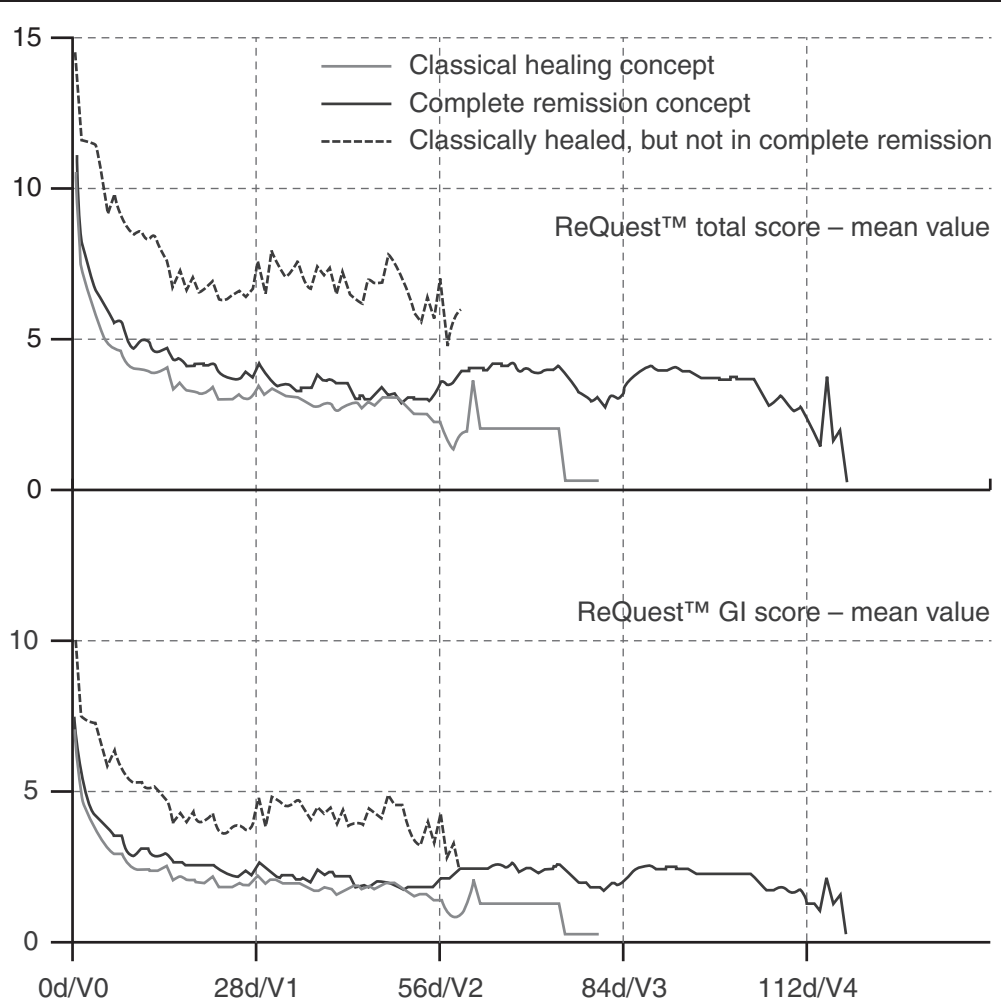

Figure 2 Change in gastrointestinal (GI) symptom burden. ReQuest ${ }^{\mathrm{TM}}$ total score \& $\mathrm{Gl}$ score; $d$, days.

in both the $\mathrm{CH}$ and $\mathrm{CR}$ study groups (Figure 3). At the end of the treatment phase, GERDyzer ${ }^{\text {Txx }}$ mean sum scores decreased by about two-thirds in each of the two treatment schedules investigated, with most of the effect achieved during the first 4 weeks of pantoprazole treatment (i.e., at the first study visit post-baseline). Substantial gains in HRQoL resulted from a major decrease in all 10 specific dimensions of GERDyzer ${ }^{\mathrm{ma}}$ (data on file).
There was no significant difference in GERDyzer ${ }^{\mathrm{rm}}$ sum scores between the two groups studied. HRQoL measured by GERDyzer ${ }^{\mathrm{Tx}}$ further improved for the $\mathrm{CH}$ and CR group during the observational phase (Figure 3), as reflected by decreasing mean sum scores. Although patients treated according to the CR concept consistently had lower GERDyzer ${ }^{\text {tx }}$ sum scores, suggesting continuously improved HRQoL, exploratively evaluated p-values

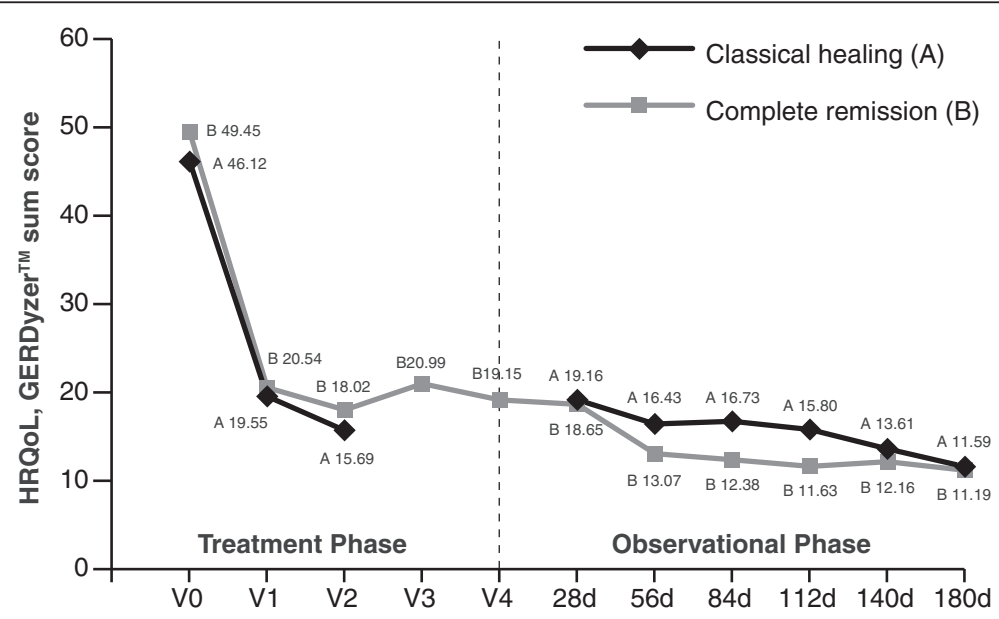

Figure 3 Change in health-related quality of life. HRQoL, GERDyzer ${ }^{T M}$ sum score during the treatment phase and the observation phase of the study; d, days (A), classical healing group; (B), complete remission group. 
were greater than the $\alpha$-level of 0.05 , indicating no significant difference in HRQoL between the two treatment concepts studied.

In order to further assess both healing concepts regarding improvements in HRQoL, GERDyzer ${ }^{\mathrm{TM}}$ scores for the $\mathrm{CH}$ and $\mathrm{CR}$ groups were analyzed in relation to scores of a subgroup deduced from $\mathrm{CH}$ patients who were endoscopically healed but not in complete remission (i.e., not achieving symptomatic relief to a level of healthy individuals). As with the ReQuest ${ }^{\mathrm{Tm}}$ scores for these three groups, GERDyzer ${ }^{\mathrm{Ts}}$ scores in the $\mathrm{CH}$ and $\mathrm{CR}$ groups were approximately only half the scores of patients endoscopically healed but not in complete remission, thus indicating notably impaired HRQoL in patients achieving esophageal healing only (data on file).

\section{Adverse events}

Because patients randomized to $\mathrm{CR}$ remained in the active treatment phase notably longer than patients allocated to $\mathrm{CH}$, a direct comparison of the incidence of adverse events has to be conducted carefully. Duration of exposure in the $\mathrm{CH}$ group was $42.3 \pm 14.8$ days compared with $56.8 \pm 31.5$ days in the CR group (ITT), which resembles an increase in exposure from $\mathrm{CH}$ to $\mathrm{CR}$ of $34 \%$. Of the 634 patients in the safety set, $175(27.6 \%)$ reported at least one treatment-emergent adverse event (TEAE), most of which were mild-to-moderate in intensity. A total of 81 of 316 patients $(25.6 \%)$ in the $\mathrm{CH}$ group and 94 of 318 patients $(29.6 \%)$ in the CR group experienced at least one TEAE, reflective of a difference in TEAE of $4 \%$ between the two groups studied. In relation to the increase in exposure of $34 \%$, a parallel increase in TEAEs of $4 \%$ suggests that most TEAEs were not causally related to the intake of pantoprazole. This was further substantiated by the investigators' causality assessment, in which $84 \%$ of TEAEs in the $\mathrm{CH}$ group and $79 \%$ of TEAEs in the CR group were considered as 'not related' or 'unlikely related' to the intake of the study medication.

\section{Discussion}

Clinical trials often include narrowly defined clinical indications and thus patient populations in order to meet regulatory or scientific requirements. In contrast, in the present study we used a scenario that was closer to reallife to investigate clinical and psychometric responses to PPI treatment in patients with endosopically-confirmed GERD [17]. This was achieved by: (1) evaluating two different treatment concepts that modelled differences in treatment intensity and compliance; and (2) applying broad inclusion criteria, which allowed assessment of overlapping GI conditions that frequently occur in selected patients and in the general population [8-10,20]. Differential assessment of patient-reported outcomes by
ReQuest ${ }^{\mathrm{Tm}}$ indicated that endoscopically healed patients who did not achieve symptomatic remission to the level of healthy individuals continued to suffer from a substantial GI symptom burden. These individuals had symptom scores that were 2-fold higher than those in patients with endoscopic healing and symptomatic remission. This was associated with notably reduced quality of life, as indicated by scores of GERDyzer ${ }^{\mathrm{Tm}}$ that were approximately 2-fold higher than those in patients with both endoscopic healing and symptomatic remission. However, this differential treatment response was not evident in the direct comparison of the original treatment groups $(\mathrm{CR}$ and $\mathrm{CH})$, for which there was no significant difference [18]. This might be a reflection of the number of patients who at each 4-week assessment point were already in symptomatic remission and were screened for endoscopic healing only. Nevertheless, the potential clinical significance of the CR concept was revealed by the cautiously implemented, pre-specified, secondary assessment of a differential subgroup of $\mathrm{CH}$ patients with endoscopic healing who did not fulfil the CR criteria.

Taken together, the analyses suggest: (1) a close correlation between HRQoL and perceived GI symptoms in GERD patients, which is consistent with previously published research [6,20]; and (2) the clinical relevance of a sufficient treatment effort aimed at symptomatic remission in addition to healing of the esophageal mucosa, i.e., until complete remission is achieved. The latter finding is further substantiated by a recently reported long-term clinical trial investigating pantoprazole in tertiary care patients over the course of 15 years [2]. Analysis indicated that the mean duration until relapse can be prolonged to approximately 7 years by the continuous administration of acid-suppressing medication.

To the best of our knowledge, we report for the first time that PPI therapy can provide improvements in HRQoL which continued to be maintained posttreatment. This occurred despite the chronic nature of erosive esophagitis in most patients [1]. However, this observation might be a consequence of the close correlation between perceived symptoms and HRQoL, and the clinically meaningful difference developing towards the end of the observational phase between the rates for relapsing erosive esophagitis (65\%) and GERD symptoms (36\%), indicative of a symptomatically silent disease in many patients despite visible damage of esophageal mucosa $[18,21]$. Thus, the delayed increase in GERD symptoms following relapse of erosive esophagitis appears to be mirrored by a trend for continuously improved HRQoL during the observational phase, until a point in time after endoscopic relapse is met when GERD symptom-related afferent input into the central nervous system exceeds the threshold for entering awareness. 
This would then trigger a coherent cognitive representation of chronically persisting or remitting symptoms, and thus provide the emotional basis for reduced HRQoL.

The high number of patients in our study with baseline dyspeptic (65\%) and/or IBS-like complaints (14\%) that resemble the types of symptoms generally attributed to functional GI disorders (FGID), such as FD and IBS, is of note. Inter-current dyspeptic and IBS-like complaints, overlapping with reflux esophagitis and GERD symptoms has been previously described in selected populations and in the general population [8-10,20]. Our data, along with those of others [20], indicate significantly increasing ReQuest $^{\mathrm{Tm}}$ scores (reflecting increasing symptomatic burden) of GERD overlapping with dyspeptic and/or IBS-like complaints. After treatment with pantoprazole, rates of patients fulfilling symptomatic Rome criteria [18] and ReQuest ${ }^{\mathrm{TM}}$ scores were generally substantially lower, indicating response of all symptom categories to PPI treatment.

Given the overlap of GERD with dyspeptic and/or IBSlike complaints, the question of whether or not individual FGID are separate conditions from GERD has been raised, and consequently different hypotheses for a possible underlying etiology have been proposed [13-16,18]. Etiological hypotheses for FGID include low-level or transient inflammation of part of the GI tract $[13,14]$, altered intestinal motility [15] or visceral hypersensitivity [16], each of which suggests the need for different therapeutic approaches in specific patient groups. Ford et al. (2010) describe a thoroughly investigated case of a more than 2-fold increase in the prevalence of dyspepsia in patients suffering from transient gastroenteritis 8 years prior to conducting their investigation [13]. One conclusion provided by the authors is that inflammation in one part of the GI tract could induce changes of the enteric nervous system of a non-inflamed part, a finding previously observed in animal models. Similar reports in humans are available on a putative pathogenic role of low-grade inflammation, identifying increased counts of mast cells in both the colon and upper GI tract of subjects with IBS, potentially leading to an abnormal interaction between mast cells and nerve fibers [14]. Such findings showing interactions between distant parts of the GI tract via the enteric nervous system or cells of the immune system may provide an explanation as to why FD and IBS were described by others as longitudinally unstable, fluctuating disease entities $[8,12]$. This cellular cross-talk might at least partially explain why improvements in reflux esophagitis have beneficial effects on overlapping symptoms suggestive of FD and IBS [18].

Evidence from distant disciplines such as molecular biology, immunology and clinical research converges on abnormal interactions between the host and the external human microbiome in the pathogenesis of IBS [14] and IBD [22], establishing an etiological interface between IBS and IBD [23]. Molecular interaction between host cells and commensal enteric bacteria, or transient acute gastroenteritis induced by specific pathogens, could lead to a continuous activation of cells of the innate and acquired immune system causing chronically perceived symptoms or lasting injury to part of the GI tract. The efficacy of antibiotic therapy in IBS and IBD provides some support for such a patho-mechanism [22,23], although theoretical interest in small intestinal bacterial overgrowth is decreasing [23]. However, our observation that FD and IBS symptomatology improve significantly during PPI treatment, although at a slower rate than the signs and symptoms of GERD [18], could possibly favour an underlying mechanism that is primarily immunemediated rather than based on neural process. Such an immune-mediated patho-mechanism would depend on sufficient time for the clonal selection, migration, homing and peripheral dispersion of immune cells. Further support for an immune-mediated patho-mechanism is provided by studies that have investigated cellular and cytokine profiles in GERD, along with the effect of PPI treatment on them $[24,25]$. In such studies, PPI therapy suppressed the expression of pro-inflammatory cytokines and chemokines, such as interleukin-8 (IL-8). Complementary studies demonstrated a reduction of the cellular-mediated inflammatory infiltrate in the esophageal epithelium, as represented by significantly decreased numbers of $\mathrm{T}$ lymphocytes and $\mathrm{CD} 8+\mathrm{T}$ lymphocytes during PPI therapy. Interestingly, both the levels of IL-8 and the number of T lymphocytes have been shown to correlate with endoscopic severity of reflux esophagitis [24,25].

Another etiological hypothesis meriting discussion is the theoretical potential for psychiatric co-morbidity, serving as a default diagnosis in patients complaining about idiopathic, unpleasant perceptions or pain located in the GI tract [26]. Such psychological disorders are described as often preceding the onset of IBS, suggesting they should not be considered as a consequence of suffering primarily from IBS [26,27]. However, GI complaints subsequent to confirmed psychiatric morbidity could be adverse drug reactions resulting from the use of psychotropic medication; they would thus be nosologically different to suffering from a functional GI disorder. Known effects of psychotropic medication occur at a compound-specific level and are variable across individual patients [28]: (1) modulation of sensory processing, involving e.g., taste [29,30], vision [31,32] and pain [33]; (2) manipulation of the endogenous emotional homeostasis [28,34-36]; and (3) the generation of further adverse reactions reported to significantly affect the GI 
tract, including bleeding [37], constipation [38-43] and diarrhea $[39,40,42]$. Unfortunately, it is not always obvious from published reports whether or not studies have been subject to potential confounding by the concomitant use of psychotropic medication [27], or if anxiety and depression might provide part of the natural spectrum of an idiopathic, chronic disease being accompanied by pain or marked discomfort [20].

FGID and GERD are reported to cluster in families $[14,44-46]$. Consequently, if an etiological genetic contribution could be proven by identifying polymorphisms of causative genes, baseline demographic data of contemporary clinical trials, such as that provided in Table 1, are currently missing the evaluation of the genetic composition of enrolled patients. However, the challenges of both determining a relevant set of genes and those of a meaningful, medically actionable, integrative analysis are well known $[44,45,47,48]$. In addition, different interpretations of competing or additive contributions of both a genetically imprinted trait matrix [48] and environmental health modifiers are amply discussed in the literature. Nevertheless, the identification of key genes could be attempted by conducting a sufficiently powered genomewide association study on FGID, investigating reasonably selected patients and conditions [48]. Omitting the known conceptual limitations of candidate gene approaches, the virtue of such an investigation would be the identification of disease predisposing loci not being limited to, or excluded by, specific a priori etiological hypotheses.

Our study provides both several strengths and certain limitations. Our study enrolled a large patient sample, avoiding narrowly defined inclusion and exclusion criteria, thus being close to a real world medical setting. This offered the opportunity of studying interrelations between both endoscopically-confirmed GERD and symptoms suggestive of FGID, and more psychometrically definable conditions like HRQoL. However, due to the focus on endoscopically-confirmed GERD (LA grades A-D), patients with endoscopy-negative GERD or those with purely functional symptoms were not included in our investigation. Despite the elaborate patient sample studied, specific subtypes of FD and IBS still tended to be relatively rare.

\section{Conclusions}

Therapy-associated changes of GI symptomatology broadly correlated with HRQoL in patients with an overlap of endoscopically-confirmed GERD and symptoms resembling FD and IBS. Furthermore, HRQoL appears to be negatively correlated with endoscopic relapses of erosive esophagitis, with the latter generally presenting initially as a silent condition. From an etiological perspective, interactions between distant parts of the GI tract via the enteric nervous system or cells of the immune system may provide an explanation for independent reports of FD and IBS presenting as longitudinally unstable, fluctuating conditions. Since the improvement observed is likely to be multifactorial, this mechanistic concept may partly explain the parallel improvements in reflux esophagitis and overlapping symptoms suggestive of FD and IBS. The previously reported observation of slower improvements in symptoms suggestive of FD and IBS could hint to a primarily immune-mediated, rather than neural, etiology, which potentially relies on the known time-requiring steps involved in clonal selection, migration, homing and peripheral dispersion of immune cells. Nevertheless, hypothesisfree exploration of underlying patho-mechanism(s) and investigating a potential molecular interface towards IBD should justify conducting a sufficiently powered and well-designed genome-wide association study. This could be conducted both in patients suffering from functional GI disorder and in those suffering from GERD with and without symptomatic overlap.

\section{Competing interests}

HM has served as speaker, consultant, and advisory board member for ALTANA, Astra Zeneca, Falk, Novartis, Nycomed GmbH (formerly ALTANA Pharma), Solvay, Steigerwald, and Wyeth. He received research funding from Nycomed GmbH (formerly ALTANA Pharma), Charité, DFG, Medtronic, and Sonnenfeld Foundation. HM owns no stocks and shares in pharmaceutical companies. CvR has no personal or funding interests. CT works for Pierrel Research. AS has served as speaker and/or consultant for ALTANA, Falk, Ferring, Janssen-Cilag, MSD, Nycomed, and Solvay. TS, RL, PS, and AT are employees of Nycomed GmbH (Nycomed: a Takeda Company).

\section{Authors' contributions}

HM, TS, PS and RL designed the clinical trial and wrote the manuscript draft. $H M, T S, P S, R L$ and AT were involved in data analysis and preparation of the manuscript. CT contributed to the planning and evaluation of the clinical trial. CVR and AS were involved in the clinical conduct and critically revised the manuscript. All authors read and approved the final manuscript.

\section{Acknowledgements}

This study was funded in full by Nycomed $\mathrm{GmbH}$. Writing support and assistance was provided by Susan Cheer, Freelance Writing Works, Queenstown, New Zealand, and by Pierrel Research Europe GmbH, Essen, Germany (formerly IFE Europe GmbH, Witten, Germany).

\section{Author details}

${ }^{1}$ Department of Medicine and Institute of Neurogastroenterology, Academic Teaching Hospital Martin Luther, Charité - Universitätsmedizin Berlin, Caspar-Theyß-Str. 27-31, 14193, Berlin, Germany. ${ }^{2}$ Nycomed GmbH, Nycomed: a Takeda Company, Konstanz, Germany. ${ }^{3}$ Tygerberg Academic Hospital, Stellenbosch University, Cape Town, South Africa. ${ }^{4}$ Department of Internal Medicine, City Hospital, Siemianowice Śląskie, Poland. ${ }^{5}$ Pierrel Research, Essen, Germany. ${ }^{6}$ Takeda Pharmaceuticals International GmbH, Zürich, Switzerland.

Received: 2 July 2013 Accepted: 24 September 2013

Published: 1 October 2013

\section{References}

1. Vakil N, van Zanten SV, Kahrilas P, Dent J, Jones R, Global Consensus Group: The Montreal definition and classification of gastroesophageal reflux disease: a global evidence-based consensus. Am J Gastroenterol 2006, 101(8):1900-1920. 
2. Brunner G, Athmann C, Schneider A: Long-term, open-label trial: safety and efficacy of continuous maintenance treatment with pantoprazole for up to 15 years in severe acid-peptic disease. Aliment Pharmacol Ther 2012, 36(1):37-47.

3. Nojkov B, Rubenstein JH, Adlis SA, Shaw MJ, Saad R, Rai J, Weinman B, Chey $W$ : The influence of co-morbid IBS and psychological distress on outcomes and quality of life following PPI therapy in patients with gastro-oesophageal reflux disease. Aliment Pharmacol Ther 2008, 27(6):473-482.

4. Holtmann G, Chassany O, Devault KR, Schmitt H, Gebauer U, Doerfler H, Malagelada JR: International validation of a health-related quality of life questionnaire in patients with erosive gastro-oesophageal reflux disease. Aliment Pharmacol Ther 2009, 29(6):615-625.

5. van Zanten SJ, Henderson C, Hughes N: Patient satisfaction with medication for gastroesophageal reflux disease: a systematic review. Can J Gastroenterol 2012, 26(4):196-204.

6. Mönnikes $\mathrm{H}$ : Quality of life in patients with irritable bowel syndrome. J Clin Gastroenterol 2011, 45(Suppl 2):S98-S101.

7. Zerbib F, Belhocine K, Simon M, Capdepont M, Mion F, Bruley des Varannes S, Galmiche JP: Clinical, but not oesophageal pH-impedance, profiles predict response to proton pump inhibitos in gastro-oesophageal reflux disease. Gut 2012, 61(4):501-506.

8. Agréus L, Svärdsudd K, Nyrén O, Tibblin G: Irritable bowel syndrome and dyspepsia in the general population: overlap and lack of stability over time. Gastroenterology 1995, 109(3):671-680.

9. Talley NJ, Dennis EH, Schettler-Duncan VA, Lacy BE, Olden KW, Crowell MD: Overlapping upper and lower gastrointestinal symptoms in irritable bowel syndrome patients with constipation or diarrhea. Am J Gastroenterol 2003, 98(11):2454-2459.

10. Bolling-Sternevald E, Aro P, Ronkainen J: Do gastrointestinal symptoms fluctuate in the short-term perspective? The Kalixanda study. Dig Dis 2008, 26(3):256-263.

11. Savarino E, Pohl D, Zentilin P, Dulbecco P, Sammito G, Sconfienza L, Vigneri $S$, Camerini G, Tutuian R, Savarino V: Functional heartburn has more in common with functional dyspepsia than with non-erosive reflux disease. Gut 2009, 58(9):1185-1191.

12. Ford AC, Forman D, Bailey AG, Axon AT, Moayyedi P: Fluctuation of gastrointestinal symptoms in the community: a 10-year longitudinal follow-up study. Aliment Pharmacol Ther 2008, 28(8):1013-1020.

13. Ford AC, Thabane M, Collins SM, Moayyedi P, Garg AX, Clark WF, Marshall JK: Prevalence of uninvestigated dyspepsia 8 years after a large waterborne outbreak of bacterial dysentery: a cohort study. Gastroenterology 2010, 138(5):1727-1736.

14. Ford AC, Talley NJ: Mucosal inflammation as a potential etiological factor in irritable bowel syndrome: a systematic review. J Gastroenterol 2011, 46(4):421-431

15. Camilleri M: Serotonin in the gastrointestinal tract. Curr Opin Endocrinol Diabetes Obes 2009, 16(11):53-59.

16. Delvaux M: Role of visceral sensitivity in the pathophysiology of irritable bowel syndrome. Gut 2002, 51(Suppl 1):i67-i71.

17. Ofman JJ: The economic and quality-of-life impact of symptomatic gastroesophageal reflux disease. Am J Gastroenterol 2003, 98(3 Suppl):S8-S14.

18. Mönnikes H, Schwan T, van Rensburg C, Straszak A, Theek C, Sander P, Lühmann R: Randomised clinical trial: sustained response to PPI treatment of symptoms resembling functional dyspepsia and irritable bowel syndrome in patients suffering from an overlap with erosive gastro-oesophageal reflux disease. Aliment Pharmacol Ther 2012, 35(11):1279-1289.

19. Bardhan KD, Berghöfer P: Look-but also listen! ReQuest ${ }^{\mathrm{TM}}$ : an essay on a new validated scale to assess the outcome of GERD treatment. Digestion 2007, 75(Suppl 1):87-100.

20. Heading RC, Mönnikes H, Tholen A, Schmitt H: Prediction of response to PPI therapy and factors influencing treatment outcome in patients with GORD: a prospective pragmatic trial using pantoprazole. BMC Gastroenterol 2011, 11:52.

21. Ronkainen J, Aro P, Storskrubb T, Johansson SE, Lind T, Bolling-Sternevald E, Graffner H, Vieth M, Stolte M, Engstrand L, Talley NJ, Agréus L: High prevalence of gastroesophageal reflux symptoms and esophagitis with or without symptoms in the general adult Swedish population: a Kalixanda study report. Scand J Gastroenterol 2005, 40(3):275-285.
22. Sartor RB: Microbial influences in inflammatory bowel diseases. Gastroenterology 2008, 134(2):577-594.

23. Quigley EM: Commensal bacteria: the link between IBS and IBD? Curr Opin Clin Nutr Metab Care 2011, 14(5):497-503.

24. De Jonge PJ, Siersema PD, Van Breda SG, Van Zoest KP, Bac DJ, Leeuwenburgh I, Ouwendijk RJ, Van Dekken H, Kusters JG, Kuipers EJ: Proton pump inhibitor therapy in gastro-oesophageal reflux disease decreases the oesophageal immune response but does not reduce the formation of DNA adducts. Aliment Pharmacol Ther 2008, 28(1):127-136.

25. Isomoto H, Nishi Y, Kanazawa Y, Shikuwa S, Mizuta Y, Inoue K, Kohno S: Immune and inflammatory responses in GERD and lansoprazole. J Clin Biochem Nutr 2007, 41(2):84-91.

26. Naliboff BD, Kim SE, Bolus R, Bernstein CN, Mayer EA, Chang L: Gastrointestinal and psychological mediators of health-related quality of life in IBS and IBD: a structural equation modeling analysis. Am J Gastroenterol 2012, 107(3):451-459.

27. Levy RL, Olden KW, Naliboff BD, Bradley LA, Francisconi C, Drossman DA, Creed F: Psychosocial aspects of the functional gastrointestinal disorders. Gastroenterology 2006, 130(3):1447-1458.

28. McAlpine DE, O'Kane DJ, Black JL, Mrazek DA: Cytochrome P450 2D6 genotype variation and venlafaxine dosage. Mayo Clin Proc 2007, 82(9):1065-1068.

29. Pollack M, Kinrys G, Krystal A, McCall WV, Roth T, Schaefer K, Rubens R, Roach J, Huang H, Krishnan R: Eszopiclone coadministered with escitalopram in patients with insomnia and comorbid generalized anxiety disorder. Arch Gen Psychiatry 2008, 65(5):551-562.

30. Citrome L: Aerosolised antipsychotic assuages agitation: inhaled loxapine for agitation associated with schizophrenia or bipolar disorder. Int J Clin Pract 2011, 65(3):330-340.

31. Kennedy JS, Jeste D, Kaiser CJ, Golshan S, Maguire GA, Tollefson G, Sanger T, Bymaster FP, Kinon BJ, Dossenbach M, Gilmore JA, Breier A: Olanzapine vs haloperidol in geriatric schizophrenia: analysis of data from a doubleblind controlled trial. Int J Geriatr Psychiatry 2003, 18(11):1013-1020.

32. Beasley CM Jr, Koke SC, Nilsson ME, Gonzales JS: Adverse events and treatment discontinuations in clinical trials of fluoxetine in major depressive disorder: an updated meta-analysis. Clin Ther 2000, 22 (11):1319-1330.

33. Apkarian AV, Bushnell MC, Treede RD, Zubieta JK: Human brain mechanisms of pain perception and regulation in health and disease. Eur J Pain 2005, 9(4):463-484.

34. Galynker II, Eisenberg D, Matochik JA, Gertmenian-King E, Cohen L, Kimes AS, Contoreggi C, Kurian V, Ernst M, Rosenthal RN, Prosser J, London ED: Cerebral metabolism and mood in remitted opiate dependence. Drug Alcohol Depend 2007, 90(2-3):166-174.

35. Margolese HC, Annable L, Dion Y: Depression and dysphoria in adult and adolescent patients with Tourette's disorder treated with risperidone. J Clin Psychiatry 2002, 63(11):1040-1044.

36. Hosseini $\mathrm{SH}$, Salehifar E: Social phobia following maprotiline: the first case report. Cases J 2009, 2:9340.

37. Coupland C, Dhiman P, Morriss R, Arthur A, Barton G, Hippisley-Cox J: Antidepressant use and risk of adverse outcomes in older people: population based cohort study. BMJ 2011, 343:d4551.

38. Brooks JO 3rd, Goldberg JF, Ketter TA, Miklowitz DJ, Calabrese JR, Bowden $\mathrm{CL}$, Thase ME: Safety and tolerability associated with second-generation antipsychotic polytherapy in bipolar disorder: findings from the systematic treatment enhancement program for bipolar disorder. J Clin Psychiatry 2011, 72(2):240-247.

39. Uher R, Farmer A, Henigsberg N, Rietschel M, Mors O, Maier W, Kozel D, Hauser J, Souery D, Placentino A, Strohmaier J, Perroud N, Zobel A, Rajewska-Rager A, Dernovsek MZ, Larsen ER, Kalember P, Giovannini C, Barreto M, McGuffin P, Aitchison KJ: Adverse reactions to antidepressants. Br J Psychiatry 2009, 195(3):202-210.

40. Gartlehner G, Thieda P, Hansen RA, Gaynes BN, Deveaugh-Geiss A, Krebs EE, Lohr KN: Comparative risk for harms of second-generation antidepressants: a systematic review and meta-analysis. Drug Saf 2008, 31(10):851-865.

41. Camilleri M: Opioid-induced constipation: challenges and therapeutic opportunities. Am J Gastroenterol 2011, 106(5):835-842.

42. Muijsers RB, Plosker GL, Noble S: Spotlight on sertraline in the management of major depressive disorder in elderly patients. CNS Drugs 2002, 16(11):789-794. 
43. Flanagan RJ: Side effects of clozapine and some other psychoactive drugs. Curr Drug Saf 2008, 3(2):115-122.

44. Morris-Yates A, Talley NJ, Boyce PM, Nandurkar S, Andrews G: Evidence of a genetic contribution to functional bowel disorder. Am J Gastroenterol 1998, 93(8):1311-1317.

45. Locke GR 3rd, Zinsmeister AR, Talley NJ, Fett SL, Melton LJ 3rd: Familial association in adults with functional gastrointestinal disorders. Mayo Clin Proc 2000, 75(9):907-912.

46. de Vries DR, ter Linde JJ, van Herwaarden MA, Smout AJ, Samsom M: Gastroesophageal reflux disease is associated with the C825T polymorphism in the G-protein beta3 subunit gene (GNB3). Am J Gastroenterol 2009, 104(2):281-285.

47. Adam B, Liebregts T, Holtmann G: Mechanisms of disease: genetics of functional gastrointestinal disorders-searching the genes that matter. Nat Clin Pract Gastroenterol Hepatol 2007, 4(2):102-110.

48. Holtmann G, van Rensburg C, Schwan T, Sander P, Siffert W: Improvement of non-steroidal anti-inflammatory drug-induced gastrointestinal symptoms during proton pump inhibitor treatment: are G-protein $\beta 3$ subunit genotype, Helicobacter pylori status, and environmental factors response modifiers? Digestion 2011, 84(4):289-298.

doi:10.1186/1471-230X-13-145

Cite this article as: Mönnikes et al:: Possible etiology of improvements in both quality of life and overlapping gastroesophageal reflux disease by proton pump inhibitor treatment in a prospective randomized controlled trial. BMC Gastroenterology 2013 13:145.

\section{Submit your next manuscript to BioMed Central and take full advantage of:}

- Convenient online submission

- Thorough peer review

- No space constraints or color figure charges

- Immediate publication on acceptance

- Inclusion in PubMed, CAS, Scopus and Google Scholar

- Research which is freely available for redistribution 